\title{
Beneficial effects of tri-lithium pyrroloquinoline quinonein on behaviors and pathology in a mouse model of Alzheimer's disease
}

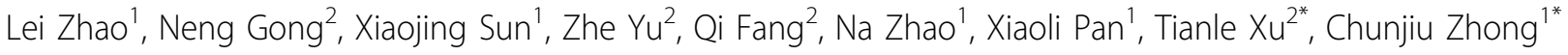 \\ From 2011 International Conference on Molecular Neurodegeneration \\ Shanghai, China. 22-24 September 2011
}

\begin{abstract}
Alzheimer's disease $(\mathrm{AD})$ is a complex disease with characteristic pathological hallmarks of senile plaques and neurofibrillary tangles, the occurrence and development of which are involved in multiple neurodegenerative processes. Conventional AD therapies target only at single disease-causing mechanisms. However, these have been mostly shown to be ineffective in recent clinical trials. Here we tested a novel strategy using a synthetic organic lithium salt, tri-lithium pyrroloquinoline quinonein ( $\left.\mathrm{Li}_{3} \mathrm{PQQ}\right)$, to modulate mulitple pathways involved in $\mathrm{AD}$ pathogenesis. The study of acute toxicity with mice showed Li3PQQ with a very low toxicity (Li3PQQ ID50 $5 \mathrm{~g} / \mathrm{kg}$ weight vs. $\mathrm{LiCl}$ ID50 $2.5 \mathrm{~g} / \mathrm{kg}$ weight). We showed that 8 weeks of daily $\mathrm{Li}_{3} \mathrm{PQQ}$ administration in the APP/ PS1 mice significantly improved the learning and memory function in the Morris water maze test and facilitated long-term potentiation. $\mathrm{Li}_{3} \mathrm{PQQ}$ significantly reduced the area and numbers of amyloid plaque and phosphorylated tau levels in cortical areas and mechanistically, it increased activities of $\mathrm{A} \beta$-binding alcohol dehydrogenase but decreased activities of glycogen synthase kinase- 3 in the transgenic mice. Therefore, $\mathrm{Li}_{3} \mathrm{PQQ}$ exhibits profound beneficial effects on cognitive impairment and pathological alterations in the AD mouse model. Our study demonstrates the effectiveness of a novel therapeutic strategy for AD through targeting at multiple disease-causing mechanisms.
\end{abstract}

\footnotetext{
* Correspondence: caoyutian1983@163.com

${ }^{1}$ Department of Neurology, Zhongshan Hospital, Fudan Univeristy, Shanghai 200032, China

${ }^{2}$ Institute of Neuroscience, State Key Laboratory of Neuroscience, Shanghai Institutes for Biological Sciences, Chinese Academy of Sciences, China Full list of author information is available at the end of the article
}

\section{Author details}

'Department of Neurology, Zhongshan Hospital, Fudan Univeristy, Shanghai 200032, China. ${ }^{2}$ Institute of Neuroscience, State Key Laboratory of Neuroscience, Shanghai Institutes for Biological Sciences, Chinese Academy of Sciences, China.

Published: 7 February 2012

doi:10.1186/1750-1326-7-S1-014

Cite this article as: Zhao et al:: Beneficial effects of tri-lithium pyrroloquinoline quinonein on behaviors and pathology in a mouse model of Alzheimer's disease. Molecular Neurodegeneration 2012 7(Suppl 1):014.
Submit your next manuscript to BioMed Central and take full advantage of:

- Convenient online submission

- Thorough peer review

- No space constraints or color figure charges

- Immediate publication on acceptance

- Inclusion in PubMed, CAS, Scopus and Google Scholar

- Research which is freely available for redistribution
C Biomed Central 